\title{
Puebla y Evangelii Gaudium: Continuidades y tensiones
}

\author{
Puebla and Evangelii Gaudium: \\ Continuities and tensions
}

Olga Consuelo Vélez Caro

\section{Resumen}

A 40 años de la celebración de la conferencia de Puebla rescatamos dos de sus principales núcleos: la liberación y la opción preferencial por los pobres. Constatamos las tensiones que supuso esa reflexión y nos preguntamos por la continuidad que han tenido, concretamente en el pontificado de Francisco. Señalar los puntos de encuentro y la vitalidad que encierran para el momento presente, es el objetivo de este artículo.

Palabras Clave: Liberación. Opción por los pobres. Compromiso social. Evangelización.

\section{Abstract}

Forty years after the celebration of the Puebla conference, we rescued two of its main nuclei: liberation and the preferential option for the poor. We note the tensions that this reflection entailed and we ask ourselves about the continuity they have had, specifically in the pontificate of Francisco. Point out the meeting points and the vitality that they contain for the present moment, is the objective of this article.

Keywords: Liberation. Option for the poor. Social commitment. Evangelization. 


\section{Introducción}

La III Conferencia General del Episcopado Latinoamericano celebrada en Puebla (27 de enero al 13 de febrero de 1979), cuyo tema fue "La evangelización en el presente y en el futuro de América Latina" forma parte del caminar de la Iglesia latinoamericana de los últimos cincuenta años. Este caminar se ha caracterizado por buscar una recepción creativa, tanto del Concilio Vaticano II como de la Exhortación Apostólica Evangelii Nuntiandi (EN), señalando como líneas prioritarias de esta recepción, la articulación de la fe con la vida - dimensión social de la fe - y la opción preferencial por los pobres. Por este motivo, en el contexto de América Latina de estos últimos años, ha sido imposible no poner en primera línea la necesaria "liberación" que exige la situación de estos pueblos. Sin embargo, ese caminar no ha sido pacífico ni acogido por todos. Críticas y persecuciones se han desatado a lo largo de estos años, manifestados en la condena a muchos teólogos y teólogas, ${ }^{1}$ en la ausencia casi total de la teología de la liberación en las facultades de teología y en la descalificación de muchos pastores y seglares que han intentado vivir esta perspectiva latinoamericana. ${ }^{2}$

Con los pontificados de Juan Pablo II y de Benedicto XVI se vivió la tensión constante entre la llamada "ortodoxia" - enseñada y promovida por las cúpulas de la Iglesia - y la praxis comprometida de inspiración latinoamericana - tenida bajo sospecha de "heterodoxa" -, aunque sin haber sido nunca condenada formalmente. ${ }^{3}$ Con el Papa Francisco, llegado "del fin del mundo",

\footnotetext{
${ }^{1}$ Una de los teólogos perseguidos fue Jon Sobrino, S. J., a quien la Congregación para la Doctrina de la Fe le notificó sobre dos de sus obras cristológicas: Jesucristo Liberador y la Fe en Jesucristo (CONGREGACIÓN PARA LA DOCTRINA DE LA FE, Notificación sobre las obras del P. Jon Sobrino, S. J.). Otros teólogos, como Leonardo Boff o teólogas como Ivone Gebara, también fueron confinados al silencio y se les impidió la enseñanza en instituciones católicas.

${ }^{2}$ Un caso emblemático puede ser el de Monseñor Oscar Arnulfo Romero, cuyo proceso de canonización no avanzó durante años hasta que en el presente pontificado se llevó a cabo (2018). De hecho el Papa Francisco dijo, en una peregrinación de la República de El Salvador a Roma, en 2015, que Monseñor Romero había sido "difamado, calumniado y ensuciado, o sea que su martirio se continuó incluso por hermanos suyos en el sacerdocio, en el episcopado" (FRANCISCO, PP., Discurso del Santo Padre Francisco a una peregrinación de la República de el Salvador).

${ }^{3}$ La teología de la liberación nunca fue condenada. Sin embargo los dos documentos de la Congregación para la Doctrina de la Fe sobre la Teología de la Liberación (CONGREGACIÓN PARA LA DOCTRINA DE LA FE, Instrucción sobre algunos aspectos de la Teología de la Liberación, 1984; CONGREGACIÓN PARA LA DOCTRINA DE LA FE, Instrucción sobre la
} 
el panorama está cambiando, no sin muchas oposiciones y desconfianzas, pero con una valoración de la reflexión teológica latinoamericana y un magisterio pontificio que sin decir explícitamente que se está refiriendo a la "teología de la liberación", ${ }_{4}^{4}$ retoma los temas centrales de la misma, reivindicando, así, este caminar teológico y esta praxis eclesial.

Mostrar algo de ese conflicto en el contexto de la Conferencia de Puebla, ${ }^{5}$ es el objetivo de este artículo. Con esto se espera resaltar la vigencia de lo allí planteado y la conexión con el actual pontificado. Para esto dividimos nuestra presentación en tres apartados. En primer lugar, mostraremos algo de las tensiones vividas en dicha conferencia. En segundo lugar, nos detendremos en dos de los elementos centrales del documento de Puebla, concretamente, en la liberación y la opción por los pobres. Finalmente, haremos algunas conexiones con las propuestas del Papa Francisco a partir del planteamiento de la dimensión social de la evangelización en su Exhortación Apostólica Evangelii Gaudium. ${ }^{6}$

\section{La Conferencia de Puebla: Tensiones y perspectivas}

A diez años de la II Conferencia General del Episcopado Latinoamericano celebrada en Medellín, se consideró oportuno celebrar una nueva conferencia. Pero su celebración obedecía a por lo menos dos tendencias dentro del episcopado: los que querían seguir profundizando en las líneas abiertas por Medellín y los que pretendían corregir "los errores y desviaciones" de dicha Conferencia. Así lo expresó el papa Juan Pablo II en el Discurso inaugural pronunciado en el Seminario Palafoxiano de Puebla el 28 de enero de 1979: Esta III Conferencia "deberá, pues, tomar como punto de partida las conclusiones de Medellín, con todo lo que tienen de positivo, pero sin ignorar las incorrectas interpretaciones a veces hechas y que exigen sereno discernimiento, oportuna crítica y claras tomas de posición".

El deseo de que esta III conferencia determinara los rumbos "verdaderos"

libertad cristiana y la liberación, 1986), sirvieron, muchas veces, de pretexto y soporte para los que la condenaban en la práctica, para no seguirla ni mucho menos enseñarla.

${ }^{4}$ Para una síntesis sobre el origen, desarrollo y consolidación de la teología de la liberación, VELEZ, O. C., El método teológico, p. 163-222.

${ }^{5}$ Para constatar esta afirmación de las dificultades y tensiones vividas en Puebla: LIBANIO, J. B., Nas pegadas de Medellín, p. 5.

${ }^{6}$ FRANCISCO, PP., Exhortación Apostólica Evangelii Gaudium. 
de la Iglesia - según el ala más conservadora - se pueden inferir del artículo de Boaventura Kloppenburg quien contando su experiencia en dicha conferencia la define así: “... Pero esta Tercera fue muy diferente, mejor preparada, más rica, más teológica, más pastoral y, sobre todo, más propiamente episcopal". ${ }^{7}$ En una nota aclaratoria señala que en Medellín los relatores de las 16 comisiones eran casi todos sacerdotes peritos o expertos en alguna materia, en cambio en Puebla, los obispos fueron los relatores (a excepción de una comisión, sobre los laicos). Y señala que en Puebla había "movimientos más o menos paralelos (...) por parte de los que pensaban tener algo así como un derecho nativo o adquirido (se decía que eran "los teólogos", simplemente, de Latinoamérica) a ser convocados oficialmente". ${ }^{8}$ Es decir, refleja lo que en verdad pasó en aquella Conferencia: no se permitió oficialmente la asesoría de los teólogos de la liberación y desde el ala conservadora se veían como algo paralelo que obstaculizaba el auténtico desarrollo de la Conferencia de Puebla.

Kloppenburg también describe en su artículo las discusiones - en tono violento y a veces agresivo - (así lo califica), que se dieron en torno al documento que se iba formulando. Con respecto a la "visión pastoral de la realidad latinoamericana", la asamblea dijo lo siguiente:

el texto es unilateral, incompleto, insatisfactorio, horizontalista, temporalista, parcial, pesimista, casi maniqueo; que no da suficiente atención a los aspectos propiamente pastorales de nuestra situación; que da el primado al hombre y no a Dios; que no será capaz de resistir al análisis crítico de los científicos; que acentúa excesivamente la polarización entre explotados y explotadores (...) que omite temas importantes como el armamentismo, la ecología y grandes grupos humanos, como los indios, los afroamericanos, los asiaticoamericanos; que no habla del peligro del marxismo, de la inmoralidad, del alcoholismo, etc... ${ }^{9}$

No menos cuestionadores fueron los aportes frente al apartado que trataba de la cristología:

el documento debe dar una doctrina clara sobre Cristo, explícita e inequívoca; que de hecho en América Latina existen actualmente diversas cristologías que no satisfacen los requerimientos de la fe cristiana bíblica

\footnotetext{
${ }^{7}$ KLOPPENBURG, B., Génesis del Documento de Puebla, p. 191.

${ }^{8}$ KLOPPENBURG, B., Génesis del Documento de Puebla, p. 191.

9 KLOPPENBURG, B., Génesis del Documento de Puebla, p. 200-201.
} 
y tradicional; que el texto presentado parece dar lugar a un falso pacifismo intelectual, sin mencionar las graves desviaciones cristológicas registradas en nuestro Continente; que en la predilección de Jesús por los pobres había lugar para tratar evangélicamente con toda clase de personas, (...) También sobre la iglesia hubo varias intervenciones: que urge deshacer sin ambages los equívocos existentes sobre la naturaleza y misión de la Iglesia, que el Documento debe rechazar categóricamente aquellas tesis que propugnan una visión de la Iglesia contraria a la que nos da la Tradición y sobre todo el Concilio Vaticano II; que es necesario denunciar, como lo hizo el Papa Juan Pablo II, la llamada 'Iglesia popular' que pretende poner la dirección de la Iglesia, su doctrina y su liturgia, en la base; que se debe aclarar en qué sentido la Iglesia 'nace del pueblo'; que hay que hablar con fuerza de la unidad de la Iglesia; que se acentúe su carácter misionero. ${ }^{10}$

Es interesante que según relata Kloppenburg, en un momento se presentó una nueva redacción de la introducción, que decía: "Este documento no intenta ser una exposición teológica, ni una programación pastoral. No pretende ser exhaustivo, es una comunicación de los Pastores de la Iglesia en América Latina, cuya preocupación es acompañar e iluminar el camino de la evangelización en nuestro Continente". ${ }^{11}$ El texto en general se colocaba más en un espíritu de búsqueda y acompañamiento, de pluralidad y diálogo. A esto, comenta Kloppenburg, que los Obispos, según ese texto, "iban a comenzar el Documento de Puebla negando su misma condición de Maestros de la Verdad que viene de Dios, en la cual precisamente había insistido tanto el Papa Juan Pablo II en su Discurso Inaugural. Todo sería puramente inductivo, cuando el Papa había sido tan insistentemente deductivo". ${ }^{12}$ Este texto fue retirado rápidamente pero el hecho de que se hubiera propuesto muestra la diversidad de enfoques que se vivían en la Conferencia y cómo la lectura que hace Kloppenburg, se sitúa del lado de los que no están totalmente de acuerdo con lo impulsado por Medellín y refuerza, con su crónica, el camino correcto que parece al final se consiguió.

El Documento final fue aprobado pero es interesante anotar que algunos temas - como el de la opción preferencial por los pobres - hubo 43 votos en contra y el de las opciones pastorales 38 (aunque se aprobaron porque se necesitaban dos tercios de los 184 obispos que votaron). En la Comisión sexta

\footnotetext{
${ }^{10}$ KLOPPENBURG, B., Génesis del Documento de Puebla, p. 200-201.

${ }^{11}$ KLOPPENBURG, B., Génesis del Documento de Puebla, p. 202.

${ }^{12}$ KLOPPENBURG, B., Génesis del Documento de Puebla, p. 202.
} 
sobre "Evangelización, liberación y promoción humana" se propuso hablar explícitamente de la Teología de la liberación. Después de varias redacciones, se sacó el término y, por consiguiente, no se hizo mención a dicha teología en el Documento final. ${ }^{13}$

Este ambiente que se acaba de describir en el desarrollo de la Conferencia de Puebla, no es ajeno a lo que el Papa Juan Pablo II manifestó en el Discurso inaugural. ${ }^{14}$ La primera parte se titula "Maestros de la Verdad" y en su desarrollo muestra lo que esto significa: A los obispos les dice que "su deber principal es ser maestros de la verdad" (I). "Vigilar por la pureza de la doctrina, base en la edificación de la comunidad cristiana, es pues junto con el anuncio del Evangelio, el deber primero e insustituible del Pastor, del Maestro de la fe" (I.1). "De vosotros, pastores, los fieles de vuestros países esperan y reclaman ante todo una cuidadosa y celosa transmisión de la verdad sobre Jesucristo (...) De este conocimiento derivarán opciones, valores, actitudes y comportamientos capaces de orientar y definir nuestra vida cristiana y de crear hombres nuevos y luego una humanidad nueva por la conversión de la conciencia individual y social" (I.2). Las preocupaciones que el Papa muestra se refieren a que "corren hoy por muchas partes - el fenómeno no es nuevo 'relecturas' del evangelio, resultado de especulaciones teóricas más bien que de auténtica meditación de la Palabra de Dios y de un verdadero compromiso evangélico. Ellas causan confusión al apartarse de los criterios centrales de la fe de la iglesia y se cae en la temeridad de comunicarlas, a manera de catequesis, a las comunidades cristianas" (I.4). Se refiere a una cristología que centre todo en la humanidad de Jesús o de relacionar su muerte con el conflicto político de su tiempo. Se teme que con esto "se calle la voluntad de entrega del Señor y aun la conciencia de su misión redentora" (I.4).

También el Papa quiere anunciar la Verdad sobre la Iglesia porque de una eclesiología bien cimentada depende una acción evangelizadora seria y vigorosa.

Como podría haber una auténtica evangelización, si faltase un acatamiento pronto y sincero al sagrado Magisterio, con la clara conciencia de que sometiéndose a él, el Pueblo de Dios no acepta una palabra de hombres sino la verdadera Palabra de Dios. Hay que tener en cuenta la importancia 'objetiva' de este Magisterio y también defenderlo de las insidias que en

\footnotetext{
${ }^{13}$ KLOPPENBURG, B., Génesis del Documento de Puebla, p. 205.

14 JUAN PABLO II, PP., Discurso del Santo Padre Juan Pablo II en la inauguración de la III Conferencia General del Episcopado Latinoamericano.
} 
estos tiempos, aquí y allá, se tienden contra algunas verdades firmes de nuestra fe católica" (I.7).

El papa señala que las diferencias vienen de separar Reino de Dios e Iglesia, comparando el Reino con el cambio estructural y el compromiso socio-político (I.8); de la llamada Iglesia popular que muestra desconfianza de la iglesia 'oficial' y se concreta en los pobres (I.8). Respecto a la verdad sobre el Hombre, el Papa señala que se cae en un humanismo ateo al reducirlo a una sola parcela de su ser y negar la dimensión esencial de su ser - el absoluto - (I.9). Como signos y constructores de la unidad señala: unidad entre los obispos (II.1) y Unidad con los sacerdotes, religiosos y pueblo fiel (II.2).

El Papa concluye su mensaje señalando las "Pistas de acción" para la acción evangelizadora de la Iglesia diciéndole a los obispos que sabe que ellos se proponen llevar a cabo "una seria reflexión sobre las relaciones e implicaciones existentes entre evangelización y promoción humana o liberación, considerando, en campo tan amplio e importante, lo específico de la presencia de la Iglesia" (III.1). Para iluminar esta reflexión, el Papa explicita que al preocuparse por la defensa o promoción de la dignidad humana, lo hace en línea de su misión, que aun siendo de carácter religioso y no social o político, no puede menos de considerar al hombre en su integridad de su ser. En este sentido la parábola del Buen Samaritano es claro ejemplo de ello. Y de esa manera no se opone el compromiso social con la evangelización pero para esto la iglesia no tiene que unirse a ninguna ideología sino hacerlo desde la verdad sobre el hombre que proclama y desde la doctrina social de la Iglesia. "Bebed, pues, hermanos, en estas fuentes auténticas" (III.4), concluye el Papa, invitando al compromiso con todo lo que atañe al ser humano pero desde la tradición eclesial.

Se necesita, por tanto, una

recta concepción cristiana de la liberación. La iglesia siente el deber de anunciar la liberación de millones de seres humanos, el deber de ayudar a que se consolide esa liberación pero siente también el deber correspondiente de proclamar la liberación en su sentido integral, profundo, como lo anunció y realizó Jesús. Liberación de todo lo que oprime al hombre, pero que es, ante todo, salvación del pecado y del maligno, dentro de la alegría de conocer a Dios y de ser conocido por Él. Liberación hecha de reconciliación y de perdón. Liberación que arranca de la realidad de ser hijos de Dios, a quien somos capaces de llamar $A b b a,{ }_{i}$ Padre! Y por la cual reconocemos en todo hombre a nuestro hermano, capaz de ser transformado en su corazón por 
la misericordia de Dios. Libración que nos empuja, con la energía de la caridad, a la comunión, cuya cumbre y plenitud encontramos en el Señor. Liberación como superación de las diversas servidumbres e ídolos que el hombre se forma y como crecimiento del hombre nuevo. Liberación que dentro de la misión propia de la Iglesia no se reduzca a la simple y estrecha dimensión económica, política, social o cultural, que no se sacrifique a las exigencias de una estrategia cualquiera, de una praxis o de un éxito a corto plazo" (III.6). Para salvar la liberación de sus ambigüedades y reduccionismos el Papa señala "la fidelidad a la Palabra de Dios, a la Tradición viva de la Iglesia, a su magisterio (III.6).

Esta detallada presentación, en cierto sentido, de lo acontecido en el desarrollo de la Conferencia y del discurso del Papa Juan Pablo II, quiere mostrar, ya vista con la perspectiva que dan los 40 años de distancia, la constante dialéctica que ha mantenido la iglesia sobre la "correcta" articulación entre evangelización y promoción humana. Aunque en la Gaudium et Spes y la Evangelii Nuntiandi se trató extensamente y en América Latina la Teología de la Liberación fundamentó suficientemente la inseparable unidad entre estos aspectos, sigue hasta hoy la dificultad de vivir "en un solo plano de la realidad, es decir, en esta historia concreta" el misterio del Dios encarnado en ella, que no opone estas dimensiones sino que las ve inseparables y mutuamente implicadas. Con el Pontificado de Francisco esto vuelve afirmarse - como lo veremos más adelante - pero no dejan de manifestarse las resistencias que son las que deseamos se superen definitivamente.

\section{Elementos liberadores del Documento de Puebla}

El Documento de Puebla consta de cinco partes: (I) Visión Pastoral de la realidad Latinoamericana; (2) Designio de Dios sobre la realidad de América Latina; (3) La evangelización en la Iglesia de América Latina. Comunión y participación; (4) Iglesia misionera al servicio de la Evangelización en América Latina; (5) Bajo el dinamismo del Espíritu: opciones pastorales. Como puede verse, la estructura del documento responde al método verjuzgar-actuar, presente en Medellín y que no se logró sacar de este documento. Por el contrario, en Santo Domingo se invierte, comenzando por lo doctrinal "Jesucristo evangelio del Padre" para después hablar de la realidad.

Aunque todo el documento nos muestra los elementos liberadores que quisiéramos destacar, nos detendremos solamente en lo que explícitamente se 
dice sobre "evangelización, liberación y promoción humana" (correspondiente a la segunda parte donde también se habla de los contenidos de la evangelización $\mathrm{y}$, por supuesto, de la verdad sobre Jesucristo, la Iglesia y el hombre, en concordancia con el discurso inaugural de Juan Pablo II). También nos detendremos en la "opción preferencial por los pobres", que está en la cuarta parte del documento, junto con la opción por los jóvenes y otras acciones para la construcción de la sociedad.

\subsection{Evangelización, liberación y promoción humana}

El apartado comienza reconociendo los esfuerzos de los cristianos por iluminar las situaciones conflictivas de América Latina desde la fe. Alienta a seguir prestando ese servicio evangelizador poniendo especial atención en "conservar y promover la comunión eclesial tanto a nivel local como universal. ${ }^{15}$ Se reconoce que desde Medellín se han logrado avances significativos. ${ }^{16}$

Se remite a la Doctrina social de la Iglesia en la que reconoce elementos de validez permanente ${ }^{17}$ pero también un carácter dinámico ${ }^{18}$ que responde a las condiciones de cada país y de cada época. En este sentido se fundamenta en la GS 42 en el que se pide a los laicos que no sean pasivos ejecutores sino activos colaboradores de los Pastores aportando su competencia profesional y científica. ${ }^{19}$

La finalidad de la DSI es la promoción y liberación integral de la persona humana, en su dimensión terrena y trascendente, contribuyendo así a la construcción del Reino último y definitivo, sin confundir, sin embargo, progreso terrestre y crecimiento del Reino de Dios. ${ }^{20}$

Para que la evangelización sea creíble debe responder a los desafíos de la realidad. Las carencias de toda índole reclaman acciones urgentes (obras asistenciales) pero esto implica un compromiso personal e institucional: coherencia, creatividad, audacia y entrega total. La conducta social es parte integrante del seguimiento de Cristo. ${ }^{21}$ La reflexión teológica y el

${ }^{15}$ DP 470.

${ }^{16} \mathrm{DP} 471$.

${ }^{17} \mathrm{DP} 472$.

${ }^{18}$ DP 473.

${ }^{19} \mathrm{DP} 473$.

${ }^{20}$ GS 39; DP 475.

${ }^{21}$ Esta frase remite a la pronunciada por Benedicto XVI en el Discurso Inaugural de la conferencia de Aparecida: "La opción preferencial por los pobres está implícita en la fe cristológica" (Discurso Inaugural 3; DAp 392). 
evangelio no pueden dejar de lado la vida concreta, personal y social. ${ }^{22}$ La promoción humana implica despertar la conciencia del hombre en todas sus dimensiones, hacerse protagonista de su propio desarrollo humano y cristiano, impulsar la organización, fomentar la comunión de bienes. Todo esto hace real la comunión y participación. ${ }^{23}$

Para lograr la coherencia entre el testimonio y el empeño por la liberación, cada iglesia particular debe organizar su pastoral social con esta finalidad. ${ }^{24} \mathrm{La}$ teología, predicación y catequesis para ser fieles y completas exige comunicar a todas las personas en forma oportuna y adecuada "un mensaje particularmente vigoroso en nuestros días sobre la liberación". ${ }^{25}$

Pasa a "discernir" en qué consiste la liberación en Cristo. Hay dos elementos complementarios e inseparables: la liberación de todas las servidumbres del pecado personal y social. ${ }^{26}$ La liberación se va realizando en la historia de nuestros pueblos y en la personal y abarca todas las dimensiones: lo social, lo político, lo económico, lo cultural y el conjunto de sus relaciones, desde el aporte específico del evangelio para que no pierda su originalidad ni sea acaparado por los sistemas ideológicos y los partidos políticos. ${ }^{27} \mathrm{La}$ liberación ha de fundarse en los tres grandes pilares: la verdad sobre Jesucristo, la verdad sobre la iglesia y la verdad sobre el hombre. ${ }^{28}$

Se explicita que se ha de llegar a la liberación del pecado con todas sus seducciones e idolatrías para no hacer inútil la cruz de Cristo pero también liberación de todo lo que impide los derechos fundamentales en la realidad concreta. ${ }^{29}$ No acude a ninguna clase de violencia ${ }^{30}$ ni a la dialéctica de la lucha de clases. ${ }^{31}$

${ }^{22}$ EN 29; DP 476.

${ }^{23}$ DP 477.

${ }^{24} \mathrm{DP} 478$.

${ }^{25}$ EN 29.

${ }^{26} \mathrm{DP} 482$.

${ }^{27}$ EN 32; DP 483.

${ }^{28}$ DP 484.

${ }^{29}$ DP 485.

${ }^{30}$ Cabe anotar que muchas veces los del ala más conservadora ejercen mucha más violencia que los del ala progresista. Parece que la pureza de fe que intentan vivir les hace ciegos a las exclusiones que hacen de todo el que no piense como ellos y la manera como a nivel social y político se comportan apoyando sistemas socio económicos que general inequidad "el sistema económico que mata" (EG 53), según el Papa Francisco; o no apoyando procesos de paz como el Colombiano, pidiendo el castigo y la muerte de los subversivos y descalificando el diálogo como medio efectivo para construir la paz.

${ }^{31}$ DP 486. 
En Puebla se reconoce que "Los Pastores de América Latina tenemos razones gravísimas para urgir la evangelización liberadora, no sólo porque es necesario recordar el pecado individual y social, sino también porque de Medellín para acá, la situación se ha agravado en la mayoría de nuestros países". ${ }^{32}$

Como ya hemos visto, la insistencia en la comunión con los obispos para mostrar fidelidad a la evangelización liberadora se pone en primer lugar. ${ }^{33}$ Sin embargo, no se olvida lo fundamental: volcar con amor su solicitud hacia los pobres, los enfermos, los desposeídos, los desamparados, los agobiados y cómo, descubriendo en ellos la imagen de Jesús 'pobre y paciente' se esfuerza en remediar sus necesidades y procura servir en ellos a Cristo. No nos engañemos: los fieles humildes y sencillos, como por instinto evangélico captan espontáneamente cuándo se sirve en la Iglesia al Evangelio y cuándo se le vacía y asfixia con otros intereses. ${ }^{34}$

La evangelización liberadora ha de llevar a los seres humanos a una liberación de todo ídolo sea: riqueza, poder, Estado, sexo, placer o cualquier creación de Dios, incluso su propio ser o razón humana. ${ }^{35}$ Sobre el ídolo de la riqueza se hace evidente en la "injusticia institucionalizada" manifestada en los crueles contrastes del lujo y la extrema pobreza de nuestros pueblos. Injusticia promovida tanto por el capitalismo liberal como por el colectivismo marxista. ${ }^{36}$

El uso totalitario del poder es una forma de idolatría y como tal la iglesia lo rechaza enteramente. ${ }^{37}$ Se reconoce la presencia de muchos regímenes autoritarios y hasta opresivos en el Continente. ${ }^{38}$ De ahí la necesidad de restablecer la justicia no sólo teórica y formalmente reconocida, sino llevada eficazmente a la práctica por instituciones adecuadas y realmente vigentes.

\subsection{Opción preferencial por los pobres}

Se sabe de los intentos de cambiar la expresión "opción" por "amor" y también el matizarla con diferentes adjetivos: solidaria, preferencial, no

\footnotetext{
${ }^{32}$ DP 487.

${ }^{33}$ DP 489.

${ }^{34}$ LG 8; DP 489.

${ }^{35}$ DP 491.

${ }^{36}$ DP 495.

${ }^{37}$ GS 75.

${ }^{38}$ DP 500.
} 
exclusiva, etc. ${ }^{39}$ Afortunadamente quedó el término opción que supone una actitud muy diferente del amor a los pobres que puede confundirse con caridad - muy cristiana - pero que no tiene la decisión estructural que supone la palabra "opción". Hay que anotar que Gustavo Gutiérrez valora el uso del término "solidaridad con los pobres" que también usa el documento porque en realidad la solidaridad no significa la inclinación paternal frente a los pobres sino el compromiso real con la lucha por su liberación. Igualmente aclara que el término "preferencial y no exclusiva", utilizado por Juan Pablo II va en consonancia con lo propuesto por la Teología de la Liberación porque se es consciente que el evangelio tiene una preferencia por los pobres pero no excluye a los privilegiados de un orden social injusto, para los cuales también es el mensaje salvador. ${ }^{40}$

Comienza este apartado afirmando la continuidad con Medellín y reconociendo el aumento de la pobreza. ${ }^{41}$ De ahí la necesidad de esta opción profética ${ }^{42}$ Se busca una conversión y purificación constantes para identificarse más con Cristo pobre y con los pobres. ${ }^{43}$ Se reconocen las persecuciones que ha traído esta opción, las tensiones y conflictos fuera y dentro de la Iglesia y las acusaciones de estar del lado de los poderos socioeconómicos y políticos o de una peligrosa desviación ideológica marxista. ${ }^{44}$ Pero no se puede renunciar a esta opción porque el mismo Jesús se hizo pobre y anunció el evangelio a los pobres. ${ }^{45}$ Por eso el servicio a los pobres es la medida privilegiada aunque no excluyente de seguimiento de $\mathrm{Cristo}^{46}$ y un servicio no solo de caridad sino de justicia. ${ }^{47}$ Por todo esto la pobreza evangélica es inherente al seguimiento ${ }^{48} \mathrm{y} \mathrm{el}$ testimonio de una iglesia pobre puede evangelizar a los ricos y desprenderlos de sus riquezas. ${ }^{49}$

\footnotetext{
${ }^{39}$ En la V Conferencia General del Episcopado latinoamericano y caribeño, la opción preferencial por los pobres se constituyó en referencia central, máxime cuando Benedicto XVI afirmó en el Discurso Inaugural de dicha conferencia que "la opción preferencial por los pobres está implícita en la fe cristológica" (Discurso Inaugural 3; DAp 392).

${ }^{40}$ GUTIÉRREZ, G., Pobres y liberación el Puebla, p. 1-2.

${ }^{41}$ DP 1135.

${ }^{42}$ DP 1138.

${ }^{43}$ DP 1140.

${ }^{44}$ DP 1139.

${ }^{45}$ DP 1141.

${ }^{46}$ DP 1145

${ }^{47}$ DP 1146.

${ }^{48}$ DP 1153.

${ }^{49}$ DP 1156.
} 
Como acciones concretas se proponen: condenar la pobreza extrema como antievangélica, ${ }^{50}$ conocer y denunciar los mecanismos generadores de pobreza ${ }^{51}$ sumar esfuerzos con otros para desarraigar la pobreza y crea un mundo más justo y fraterno, ${ }^{52}$ apoyar a las organizaciones que promueven el bien común ${ }^{53}$ y a los pueblos indígenas. ${ }^{54}$ Previamente se habían señalado todos los que hoy padecen pobreza: campesinos, obreros, marginados de la ciudad $\mathrm{y}$, especialmente, la mujer de esos sectores por su condición de doblemente oprimida y marginada. ${ }^{55}$

Como puede verse, Puebla no "espiritualiza" la pobreza. Una opción por los pobres es una opción por los pobres reales. Eso no significa que se ignore la necesaria actitud de una pobreza espiritual, entendida como estar abierto a Dios, pero siempre como noción complementaria porque "solo entendiendo lo afirmado sobre los pobres materiales puede comprenderse la noción de pobreza espiritual; solo se da el verdadero carácter espiritual de las bienaventuranzas cuando se descubre que Dios es el fundamento del privilegio de los pobres" ${ }^{56}$

\subsection{Evangelización y liberación: un binomio inseparable}

Hemos visto como en el Documento de Puebla se habla explícitamente de la liberación y de los pobres. Es que sin esa referencia explícita a la situación real de los pobres, no se puede entender el contenido de la liberación. Y sin esas dos referencias, la evangelización no puede tocar la realidad verdaderamente. Quedaría como un "barniz superficial", haciendo eco de la expresión de $\mathrm{EN},{ }^{57}$ porque no habría una verdadera encarnación del mensaje salvador en la realidad concreta que viven las mujeres y varones de cada tiempo presente. El término "liberación integral" que se asumió para superar la polémica frente a los que consideraban que el evangelio se reduce si solo se entiende la liberación en su dimensión social, puede ser extremamente peligroso si por

\footnotetext{
${ }^{50}$ DP 1159.

${ }^{51}$ DP 1160.

${ }^{52}$ DP 1161.

${ }^{53}$ DP 1163.

${ }^{54}$ DP 1164.

${ }^{55}$ Nota 2, DP 1135.

${ }^{56}$ GUTIÉRREZ, G., Pobres y liberación en Puebla, p. 7.

${ }^{57}$ EN 20: "Posiblemente, podríamos expresar todo esto diciendo: lo que importa es evangelizar - no de una manera decorativa, como un barniz superficial, sino de manera vital, en profundidad y hasta sus mismas raíces".
} 
integral se entiende exclusivamente lo religioso o espiritual. Es urgente, por tanto, mantener la totalidad de lo que significa una liberación integral.

De hecho, la teología de la liberación

siempre ha hablado de totalidad y complejidad del proceso de liberación. Se trata de un proceso único con distintas dimensiones (económica, social, política, moral, religiosa, espiritual). Estas dimensiones se implican, son inseparables. Si se separan se cae en posiciones idealistas, espiritualistas, alienantes o bien en posiciones parciales, de eficacia solo a corto plazo. Se debe salvar, pues, la complejidad, la totalidad y la inseparabilidad de las dimensiones de la liberación, la integralidad..$^{58}$

\section{El Papa Francisco y su mensaje social y liberador ${ }^{59}$}

El Papa Francisco explícitamente no habla de Teología de la Libración. Pero su discurso y sus opciones prioritarias hacen resonar esta teología ${ }^{60} y$, por consiguiente la continuidad con el caminar latinoamericano trazado por las Conferencias Episcopales, especialmente, Medellín y Puebla. Para mostrar esta continuidad nos centramos en la Exhortación Apostólica Evangelii Gaudium (EG). ${ }^{61}$

Lo primero que llama la atención es el espacio que le dedica a la dimensión social de la evangelización en su primera Exhortación Apostólica. Todo el capítulo cuarto está dedicado a ella. ${ }^{62}$ Además, los pobres y el compromiso con su inclusión social, son eje central. Presentaremos lo que el Papa desarrolla en este capítulo para al final mostrar la continuidad con Puebla y los desafíos para nuestro presente.

\subsection{El anuncio del Kerygma y la dimensión social del Evangelio}

La labor misionera de la Iglesia comienza con el anuncio del kerygma.

\footnotetext{
${ }^{58}$ GUTIÉRREZ, G., Pobres y liberación en Puebla, p. 9.

${ }^{59}$ Las ideas de este apartado fueron expuestas en un capítulo de libro publicado en 2015. VELEZ, O. C., The Social Dimension of Evangelization, p. 189-198.

${ }^{60}$ Muchos comentarios y reflexiones muy positivas de teólogos y teólogas de la liberación sobre el Papa Francisco pueden encontrarse en www.amerindiaenlared.org.

${ }^{61}$ Publicada el 24 de noviembre de 2013.

${ }^{62}$ Ochenta y un (81) números de los doscientos ochenta y ocho (288) que constituyen la Exhortación Apostólica Evangelli Gaudium.
} 
Y este anuncio tiene ineludiblemente una dimensión social porque "la vida comunitaria y el compromiso con los otros" son el corazón mismo del Evangelio. ${ }^{63}$ Ahora bien, estas afirmaciones no son una exigencia nueva. Nos remiten a la Exhortación Apostólica de Paulo VI, Evangelii Nuntiandi, documento obligado de referencia para referirnos a la evangelización. En este documento se pregunta por la eficacia de la Buena nueva para estos tiempos y los métodos adecuados para anunciarla ${ }^{64}$ y responde, remitiéndonos a Jesús evangelizador como fundamento de una Iglesia evangelizadora, destacando que el núcleo y centro de su Buena Nueva es la salvación, don de Dios que es liberación de todo lo que oprime al hombre ${ }^{65}$ mediante signos, destacando de entre ellos el que los pequeños, los pobres son evangelizados. ${ }^{66}$

Los contenidos de la evangelización se fundamentan en el amor de Dios Padre-Madre revelado en Jesucristo mediante el Espíritu Santo ${ }^{67}$ y en el mensaje de liberación de las situaciones inhumanas que afectan a millones de seres humanos que "los condenan a quedar al margen de la vida: hambres, enfermedades crónicas, analfabetismo, depauperación, injusticia en las relaciones internacionales y, especialmente, en los intercambios comerciales, situaciones de neocolonialismo económico y cultural, a veces tan cruel como el político, etc." ${ }^{68}$ Cabe anotar que en este mismo numeral de la EN se dice que esta preocupación proviene, especialmente, de los "Obispos del Tercer Mundo". Curiosamente, hoy, es un Papa nacido en el continente latinoamericano, el que vuelve a insistir en la explicitación de la dimensión social de la evangelización porque de no hacerlo "se corre el riesgo de desfigurar el sentido auténtico e integral que tiene la misión evangelizadora". ${ }^{69}$

Ese mensaje de liberación que constituye la evangelización conecta inmediatamente con la relación fuerte entre evangelización y promoción humana: a nivel antropológico, porque el ser humano no es un ser abstracto sino un ser sujeto a los problemas sociales y económicos; a nivel teológico porque el plan de la redención llega hasta situaciones muy concretas de injusticia; $y$, a nivel evangélico, porque la caridad no es ajena a la promoción

\footnotetext{
${ }^{63} \mathrm{EG} 177$.

${ }^{64} \mathrm{EN} 4$.

${ }^{65}$ EN 9.

${ }^{66} \mathrm{EN} 12$.

${ }^{67}$ EN 26.

${ }^{68} \mathrm{EN} 30$.

${ }^{69} \mathrm{EG} 176$.
} 
de la justicia y la paz. ${ }^{70}$ De esta manera podemos ver cómo la tradición eclesial ha ido profundizando en el sentido complejo e integrador de la evangelización y ya es patrimonio de fe, esa íntima conexión entre salvación cristiana y liberación humana porque - por el misterio de la Encarnación -, nada de lo que no es asumido puede ser redimido (San Irineo).

El Dios Trinidad en quién creemos nos convoca necesariamente a la salvación en comunidad y eso refuerza la "íntima conexión entre evangelización y promoción humana, que necesariamente debe expresarse y desarrollarse en toda acción evangelizadora". ${ }^{71}$ Los textos de la Sagrada Escritura así lo confirman: "Lo que hiciste a uno de estos hermanos míos más pequeños, a mí me lo hiciste" (Mt 25,40). ${ }^{72}$ El Reino de Dios anunciado por Jesús consiste ante todo en

\begin{abstract}
amar a Dios que reina en el mundo. En la medida que Él logre reinar entre nosotros, la vida social será ámbito de fraternidad, de justicia, de paz, de dignidad para todos. ${ }^{73}$ Este anuncio de la Buena Nueva tiene que abarcar toda la existencia, todas las personas, todas las dimensiones de la convivencia y todos los pueblos. Nada de lo humano puede resultar extraño. ${ }^{74}$
\end{abstract}

Con todas estas afirmaciones el Papa Francisco está explicitando la sentida necesidad de decir una palabra, desde la fe, sobre la realidad social. Si todo lo humano es campo de acción del mandato evangelizador, la palabra social de la Iglesia tiene sentido y razón de ser. Los cristianos han de decir una palabra cualificada sobre la realidad social en articulación con las ciencias pero, sobre todo, con la exigencia evangélica de influir en esta realidad donde los seres humanos han de vivir y disfrutar de todas las cosas. De esta manera se comprende que la salvación ofrecida en Cristo no es para las almas que buscan el cielo sino para los seres humanos que viviendo en este mundo, han de encargarse de todo lo que "pertenece al orden social y a la obtención del bien común". ${ }^{75}$

\footnotetext{
${ }^{70} \mathrm{EN} 31$.

${ }^{71}$ EG 178.

${ }^{72}$ EG 179.

${ }^{73}$ EG 180.

${ }^{74}$ DAp 380; EG 181.

${ }^{75}$ EG 182.
} 
Ahondando en esa dimensión social del Kerygma, el Papa señala que aunque el orden justo de la sociedad y del Estado es tarea principal de la política, "la Iglesia ni puede ni debe quedar al margen en la lucha por la justicia" ${ }^{76} \mathrm{e}$ insta a todos los cristianos, pero también a los Pastores, a preocuparse por la construcción de un mundo mejor. ${ }^{77}$ Ahora bien, deja claro dos cosas: (1) la Iglesia ha de decir una palabra social - la Doctrina social de la Iglesia $-{ }^{78}$ la Iglesia "no tiene el monopolio en la interpretación de la realidad social o la propuesta de soluciones a los problemas contemporáneos". ${ }^{79}$ La tarea humana es de todos y la Iglesia ha de colaborar con otros, eso sí, ofreciendo su palabra con audacia y valentía, pero también con humildad y capacidad de aprender de los demás.

\subsection{La Inclusión social de los pobres}

Como ya lo anotamos al inicio, la Exhortación coloca a los pobres en el centro de la preocupación social de la Iglesia y en su compromiso evangelizador. Si recordamos uno de los textos más trabajados por la Teología de la Liberación fue el del Ex 3,7ss: "He visto la aflicción de mi pueblo en Egipto, he escuchado su clamor ante sus opresores y conozco sus sufrimientos. He bajado para librarlo (...)". Precisamente con este texto el Papa comienza a desarrollar este tema. El Señor nos llama a ser sus instrumentos para escuchar al pobre y no podemos hacernos sordos a ese clamor. Más aún, la cita de Santiago $(5,4)$ a la que se alude recoge la indignación ética frente a las injusticias cometidas contra los pobres.$^{80}$ Responder al clamor de los pobres implica "tanto la cooperación para resolver las causas estructurales de la pobreza y promover el desarrollo integral de los pobres, como los gestos más simples y cotidianos de solidaridad ante las miserias muy concretas que encontramos". ${ }^{81}$ Además esta escucha del pobre es también escucha a los pueblos pobres que no pueden estar al margen simplemente por contar con menos recursos naturales o menos desarrollo. ${ }^{82}$

\footnotetext{
${ }^{76}$ DCE 28.

${ }^{77}$ EG 183.

${ }^{78}$ EG 2.

${ }^{79}$ EG 184.

${ }^{80} \mathrm{EG} 187$.

${ }^{81}$ EG 188.

${ }^{82}$ EG 190.
} 
El Papa continúa ahondando en las consecuencias del compromiso social de la Iglesia, cuando pone en su centro la realidad de los pobres. Se refiere a la solidaridad como "la reacción espontánea de quien reconoce la función social de la propiedad y el destino universal de los bienes como realidades anteriores a la propiedad privada. La solidaridad es, en realidad, "un devolverle al pobre lo que le corresponde". ${ }^{83}$ Más aún, el mensaje del evangelio nos invita a estremecernos desde las entrañas ante el dolor ajeno y a que el evangelio de la misericordia "resuene con fuerza en la vida de la Iglesia" ${ }^{84}$ Son tan claros los textos que hablan de la misericordia que el Papa pregunta "¿para qué complicar lo que es tan simple?". Los textos bíblicos invitan con tanta contundencia al amor fraterno, al servicio humilde y generoso, a la justicia, a la misericordia con el pobre que no debemos hacer teorías que nos alejan de la realidad sino responder a ella con radicalidad. Más aún el Papa llama la atención sobre los que se preocupan de la "ortodoxia" siendo tan pasivos, indulgentes o cómplices respecto a situaciones de injusticia intolerables y a los regímenes políticos que las mantiene. ${ }^{85}$

Como prueba de la centralidad de los pobres y la opción por ellos, el Papa recuerda la carta de Pablo a los Gálatas donde el criterio para saber si no había "corrido su carrera en vano" se define en "no olvidarse de los pobres" (Gál 2,10). Por tanto, aunque se tengan muchas deficiencias en el anuncio del Evangelio, lo que sigue siendo un signo inequívoco es la "opción por los últimos, por aquellos que la sociedad descarta y desecha". ${ }^{86}$ Los rostros de los pobres como en otros documentos del Magisterio Latinoamericano ${ }^{87}$ también se señalan aquí: "los sin techo, los toxico dependientes, los refugiados, los pueblos indígenas, los ancianos, los migrantes, los que sufren el flagelo de la trata de personas, las mujeres, etc. ${ }^{88}$

El papa no solamente da tanta importancia a la inclusión social de los pobres sino que también recuerda el lugar privilegiado que ellos ocupan en la vida de la Iglesia. El lugar preferente de los pobres no es por sus méritos, ni por su bondad sino por el querer mismo de Dios que les otorga "su primera misericordia". Ellos efectivamente participan del sensus fidei del pueblo de

\footnotetext{
${ }^{83}$ EN 189.

${ }^{84}$ EG 193.

${ }^{85}$ EG 194.

${ }^{86}$ EG 195.

${ }^{87}$ DP 31-39; DSD 179; DAp 65.

${ }^{88}$ EG 210-213.
} 
Dios y conocen en su propia experiencia los dolores del Cristo sufriente. Por eso ellos nos evangelizan. Por tanto, la opción por los pobres es una categoría teológica que orienta decisivamente nuestra vida cristiana. ${ }^{89}$

Por su carácter teológico, la opción por los pobres no se refiere a meras acciones de promoción y asistencia sino a ese encuentro personal con el pobre y sus necesidades, su cultura, su forma de vivir la fe. No es una utilización de los pobres, ni una ideología al servicio de nuestros intereses. Es la vivencia teologal y contemplativa de la identificación de Cristo en su vida histórica con ellos. ${ }^{90}$

\subsection{Sobre las cuestiones económicas}

El sistema económico vigente forma parte de la dimensión social de la evangelización. Y las afirmaciones del Papa en este sentido, son contundentes: el presente modelo económico es "exitista" y "privatista" e impide que los "lentos, débiles o menos dotados puedan abrirse camino en la vida" ${ }^{91}$ Las causas estructurales de la pobreza no se resuelven sin "renunciar a la autonomía absoluta de los mercados y a la especulación financiera y atacando las causas estructurales de la inequidad". 92 "La dignidad de la persona y el bien común son las cuestiones que deberían reestructurar toda política económica". ${ }^{93}$ Palabras como ética, solidaridad, distribución de bienes, etc., molestan al sistema imperante. No se puede confiar más en "la mano invisible del mercado" que sólo apunta a buscar crecimiento económico sin tomar en cuenta que se requiere algo más que esa libre competencia para crear programas y proyectos que defiendan a los más débiles. ${ }^{94}$ Adelantándose a las críticas que él intuía iba a suscitar, ${ }^{95}$ dice que no pretende ofender a nadie con sus palabras, ni mira a las personas gestoras de estas economías como enemigos, sino que desea que "aquellos que están esclavizados por una mentalidad individualista, indiferente y egoísta, puedan liberarse de esas cadenas indignas y alcancen

\footnotetext{
${ }^{89}$ EG 197-198.

${ }^{90}$ EG 197.

${ }^{91}$ EG 209.

${ }^{92} \mathrm{EG} 202$.

${ }^{93}$ EG 203.

${ }^{94}$ EG 204.

${ }^{95}$ Refiriéndose a la EG, un locutor de CNN afirmó: “el Papa Francisco está predicando puro marxismo...".
} 
un estilo de vida y de pensamiento más humano, más noble, más fecundo que dignifique su paso por esta tierra". ${ }^{96}$

El Papa continua en este apartado serias y profundas reflexiones sobre el bien común y la paz social ${ }^{97}$ y sobre la urgencia del diálogo fecundo para la construcción de la paz. ${ }^{98}$ No nos detendremos en estos apartados porque con los anteriores hemos profundizado en los temas que nos convocan en esta reflexión: la liberación y la opción por los pobres.

\section{Conclusión}

El recorrido que hemos hecho nos ha permitido ver la continuidad entre el Documento de Puebla y los planteamientos del Papa Francisco. Prácticamente se está hablando de la misma realidad, con la fuerza profética que implica y explicitando muy abiertamente la necesaria encarnación de la fe en todas las realidades que vivimos, especialmente, en la que tiene que ver con la vida digna para todos y todas, comenzando por las condiciones básicas para vivir, sin olvidar todas las demás dimensiones que constituyen la integralidad de los seres humanos.

Hemos querido hacer el contraste con el Discurso inaugural de Juan Pablo II en la conferencia de Puebla porque sin negar que allí se explicita mucho de lo que acabamos de decir - la necesaria referencia a lo social - el contexto en sí, lo supedita a otra manera de situarse ante la fe, a una ortodoxia que pasa primero por el conocimiento y luego por la práctica y a una postura eclesial que se cree poseedora de la verdad y pretende enseñarla inequívocamente. Muy distinta ha sido la postura del Papa Francisco que sitúa su palabra con apertura de dejarse complementar por los otros saberes, no solo dentro del mismo episcopado:

Tampoco creo que deba esperarse del magisterio papal una palabra definitiva o completa sobre todas las cuestiones que afectan a la iglesia y el mundo. No es conveniente que el Papa reemplace a los episcopados locales en el discernimiento de todas las problemáticas que se plantean en sus territorios. En este sentido, percibo la necesidad de avanzar en una saludable "descentralización". ${ }^{99}$

\footnotetext{
${ }^{96} \mathrm{EG} 208$.

${ }^{97}$ EG 271-237.

${ }^{98}$ EG 238-258.

${ }^{99}$ EG 16.
} 
Sino también con los otros saberes, diciendo explícitamente que la Iglesia no tiene todo el conocimiento de la realidad: "Sobre muchas cuestiones concretas la Iglesia no tiene por qué proponer una palabra definitiva y entiende que debe escuchar y promover el debate honesto entre los científicos, respetando la diversidad de opiniones". ${ }^{100}$

En conclusión, podríamos afirmar que no estamos en tiempos de intimismos o espiritualismos que nos alejan de la realidad. Estamos en el tiempo del Espíritu que de la misma manera como guio a Jesús en su vida histórica, hoy de nuevo nos oriente a evangelizar por las sendas de los pobres, de la liberación, de la buena noticia: "El Espíritu del Señor está sobre mí. Él me ha ungido para traer Buenas Nuevas a los pobres, para anunciar a los cautivos su libertad y a los ciegos que pronto van a ver. A despedir libres a los oprimidos y a proclamar el año de la gracia del Señor" (Lc 4,18). De nuestra fidelidad al soplo del Espíritu depende, en gran parte, esta primavera eclesial que parece estar llegando con el Papa Francisco, en continuidad con el caminar de la Iglesia latinoamericana y que, con esperanza, deseamos que se quede.

\section{Referencias bibliográficas}

BENEDICTO XVI, PP. Deus Caritas Est. 2005. Disponible en: $<$ http:// w2.vatican.va/content/benedict-xvi/es/encyclicals/documents/hf_ben-xvi_ enc_20051225_deus-caritas-est.html>. Acceso en: 25 ene. 2019.

CELAM. Las Cinco Conferencias Generales del Episcopado Latinoamericano. Bogotá: CELAM, 2014.

CONCÍLIO VATICANO II. Gaudium et Spes. Bilbao: Mensajero, 1981.

CONCÍLIO VATICANO II. Lumen Gentium. Bilbao: Mensajero, 1981.

CONGREGACIÓN PARA LA DOCTRINA DE LA FE. Instrucción sobre algunos aspectos de la Teología de la Liberación, 1984. Disponible en: $<$ http://www.vatican.va/roman_curia/congregations/cfaith/documents/rc con_cfaith_doc_19840806_theology-liberation_sp.html>. Acceso en: 14 ene. 2019.

CONGREGACIÓN PARA LA DOCTRINA DE LA FE. Instrucción sobre la libertad cristiana y la liberación, 1986. Disponible en: <http://www.

${ }^{100}$ LS 61. 
vatican.va/roman_curia/congregations/cfaith/documents/rc_con_cfaith_ doc_19860322_freedom-liberation_sp.html>. Acceso en: 14 ene. 2019.

CONGREGACIÓN PARA LA DOCTRINA DE LA FE. Notificación sobre las obras del P. Jon Sobrino, S.J., 2006. Disponible en: <http://www. vatican.va/roman_curia/congregations/cfaith/documents/rc_con_cfaith_ doc_20061126_notification-sobrino_sp.html>. Acceso en: 24 ene. 2019.

FRANCISCO, PP. Laudato Si, 2015. Disponible en: <http://w2.vatican.va/ content/francesco/es/encyclicals/documents/papa-francesco_20150524_enciclica-laudato-si.html>. Acceso en: 25 ene. 2019.

FRANCISCO, PP. Discurso del Santo Padre Francisco a una peregrinación dela República de El Salvador. Disponible en: <http://w2.vatican. $\mathrm{va} /$ content/francesco/es/speeches/2015/october/documents/papa-francesco_20151030_el-salvador.html>. Acceso en: 25 ene. 2019.

FRANCISCO, PP. Exhortación Apostólica Evangelii Gaudium, 2013. Disponible en: <http://w2.vatican.va/content/francesco/es/apost_exhortations/ documents/papa-francesco_esortazione-ap_20131124_evangelii-gaudium. html>. Acceso en: 25 ene. 2019.

GUTIÉRREZ, G. Pobres y liberación el Puebla. Selecciones de Teología, v.19, n.76, p. 1-32, oct./dic. 1980. Disponible en: <http://www.seleccionesdeteologia.net/selecciones/llib/vol19/76/076_gutierrez.pdf > . Acceso en: 25 ene. 2019.

JUAN PABLO II, PP. Discurso del Santo Padre Juan Pablo II en la inauguración de la III Conferencia General del Episcopado Latinoamericano. Puebla, México. Domingo 29 de enero de 1979. Disponible en: $<$ http://w2.vatican.va/content/john-paul-ii/es/speeches/1979/january/documents/hf_jp-ii_ spe_19790128_messico-puebla-episc-latam.html>. Acceso en: 25 ene. 2018.

KLOPPEnBURG, B. Génesis del Documento de Puebla. Revista Medellín, v.5, n.17-18, p. 190-207, ene/jun. 1979.

LIBANIO, J. B. Nas pegadas de Medellín: as opções de Puebla. Cadernos de Teologia Pública, v.5, n. 37, 2008.

PABLO VI, PP. Exhortación Apostólica Evangelii Nuntiandi, 1975. Disponible en: $<$ http://w2.vatican.va/content/paul-vi/es/apost_exhortations/documents/hf_p-vi_exh_19751208_evangelii-nuntiandi.html >. Acceso en: 24 ene. 2019. 
VELEZ, O. C. El método teológico. Fundamentos. Especializaciones. Enfoques. Bogotá: Pontificia Universidad Javeriana, 2008.

VELEZ, O. C. The Social Dimension of Evangelization. An incontrovertible Commitment. In: KRÄMER, K.; VELLGUTH, K. (Eds.). Evangelii Gaudium. Voices of the Universal Church. One World Theology. Quezon City: Claretian Communications Foundation, Inc., 2015. p. 189-198.

Olga Consuelo Vélez Caro

Doutora em Teologia pela Pontifícia Universidade Católica do Rio de Janeiro Docente do Departamento de Teologia da Pontificia Universidad Javeriana Bogotá - Colombia E-mail: ocvelez@yahoo.es

Recebido: $28 / 01 / 19$

Aprovado: 08/03/19 